\title{
Subcutaneous Myeloma Deposit in the Region of an Arteriovenous Fistula
}

\author{
Arteriyovenöz Fistül Bölgesinde Deri Altı Miyelom Birikimi
}

Petar Djuric ${ }^{1}$, Aleksandar Jankovic ${ }^{1}$, Zoran Milojevic ${ }^{2}$, Katarina Markovic ${ }^{2}$, Slavisa Sekulic ${ }^{3}$, Milan Pantelic ${ }^{4}$, Jelena Tosic Dragovic ${ }^{1}$ Ana Bulatovic ${ }^{1}$, Nada Dimkovic ${ }^{1,5}$

${ }^{1}$ Zvezdara University Medical Center, Department of Nephrology, Belgrade, Serbia

${ }^{2}$ Zvezdara University Medical Center, Department of Hematology, Belgrade, Serbia

${ }^{3} Z$ vezdara University Medical Center, Department of Surgery, Belgrade, Serbia

${ }^{4}$ Zvezdara University Medical Center, Department of Radiology, Belgrade, Serbia

${ }^{5}$ Belgrade of University Faculty of Medicine, Department of Nephrology, Belgrade, Serbia

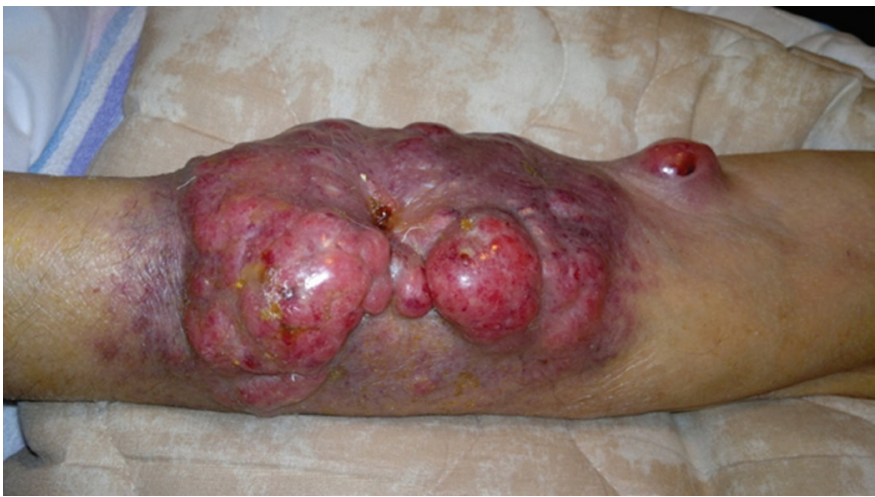

Figure 1. Local finding on the skin of the left forearm: note that the entire circumference of the forearm was affected by tumorlike changes.

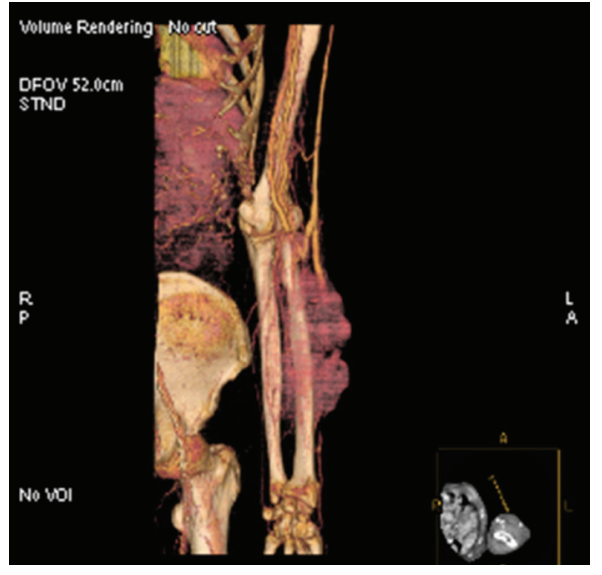

Figure 2. Multislice computer tomography angiography of the arteriovenous fistula.
A 78-year-old male was hospitalized in October 2013 due to renal failure. Soon thereafter, light-chain deposition disease was confirmed (lambda type DSSS IIIA, ISS III). A high-dose DEXA protocol was introduced and he received 11 protocols during the following 12 months. In October 2014 he commenced maintenance hemodialysis (HD) via a distal arteriovenous fistula (AVF). In March 2015 he noticed swelling of the fistula region. Although the AVF was functional, local findings on the skin deteriorated within 1 month (Figure 1). Multislice computer tomography demonstrated highly vascularized tumor-like changes originating from the AVF (Figure 2). The patient underwent aspiration biopsy of the skin and more than 10\% lymphoplasmacytic cells were found by microscopy. The finding was confirmed by histology (Figure 3). A PET scan was not available. At that time, he was very frail and no specific therapy was recommended by the hematologist. The patient died within 3 weeks.

Presentation of extramedullary subcutaneous light-chain deposition surrounding an AVF may be a potential link between light-chain deposition disease and augmented circulation, thus giving a preferential site for tumor growth [1]. Hematogenous spread (metastasis) to the AVF region is plausible considering the intact adjacent bone and repeated trauma of the multiple cannulation of the AVF. Such repeated trauma gives a good environment for tumor seeding. Our conclusion is that patients 


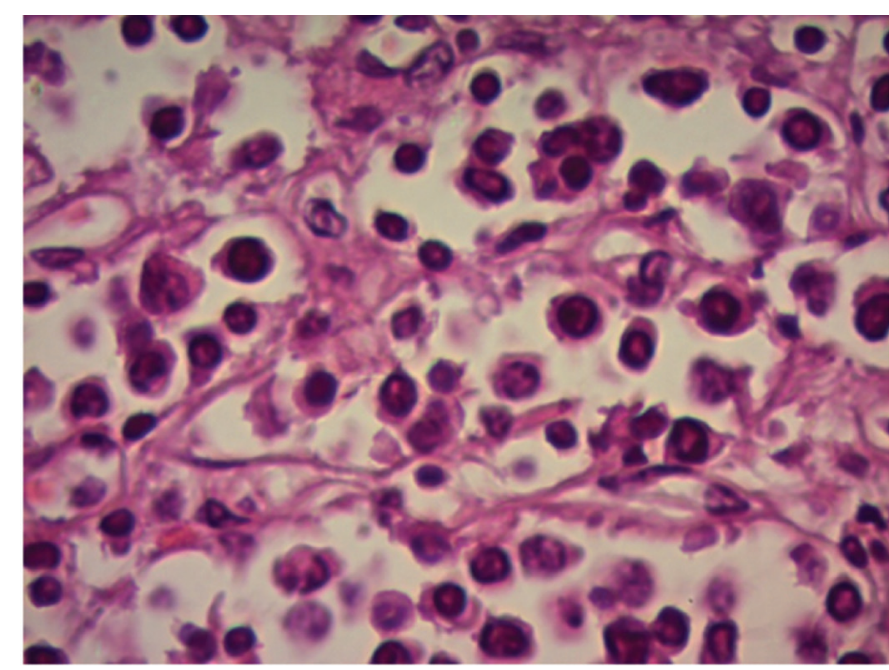

Figure 3. Histology of the affected skin: multiple lymphoplasmacytic cells. with light-chain deposition disease and end-stage renal disease may be considered for peritoneal dialysis instead of HD.

Keywords: Distal arteriovenous fistula, Multislice computer tomography, Hemodialysis

Anahtar Sözcükler: Distal arteriyovenöz fistül, Çok kesitli bilgisayarlı tomografi, Hemodiyaliz

Informed Consent: Was obtained from the patient.

Conflict of Interest: The authors of this paper have no conflicts of interest, including specific financial interests, relationships, and/or affiliations relevant to the subject matter or materials included.

\section{References}

1. Boshell D, Sabharwal R, Keen R, Coleman P, Vladica P, Roger SD. Fistula dysfunction secondary to a subcutaneous myelomatous deposit. Nephrol Dial Transplant 2005;20:2827-2829. 